\title{
As marcas da migração internacional no Vale do Rio Doce pelos utensílios domésticos
}

\author{
Ricardo Alves ${ }^{1}$ \\ Sueli Siqueira ${ }^{2}$
}

Resumo: $\mathrm{O}$ artigo busca identificar e evidenciar marcas (i) materiais que a emigração em seis cidades do Vale do Rio Doce inscreve nesses territórios pelos sujeitos e grupos que migram para os Estados Unidos. Para tanto, aciona as teorias da migração internacional e as conjuga com os estudos territoriais. Também se vale da fotografia com instrumental de pesquisa e linguagem expositiva dos resultados ancorada na Semiótica como metodologia de análise das imagens. Neste artigo a série fotográfica dos utensílios domésticos é analisada, revelando a existência de marcantes aspectos que (re) configuram um território historicamente marcado pela vivencia da migração.

Palavras-chave: Emigração internacional. Território. Fotografia. Semiótica.

\section{The marks of international migration in the Vale do Rio Doce by household items}

\begin{abstract}
The article seeks to identify and evidence (i) material marks that emigration in six cities in the Rio Doce Valley inscribes in these territories by the subjects and groups that migrate to the United States. For this purpose, it activates the theories of international migration and combines them with territorial studies. It also uses photography as a research tool and expository language of the results anchored in Semiotics as a methodology for analyzing images. In this article, the photographic series of household items is analyzed, revealing the existence of striking aspects that (re) configure a territory historically marked by the experience of migration.
\end{abstract}

Keywords: International emigration. Territory. Photography. Semiotics.

${ }^{1}$ Universidade do Vale do Rio Doce (Univale), Governador Valadares-MG, Brasil (jornalista@hotmail.com).

2 Idem (suelisiqueira.gv@gmail.com). 


\section{Las marcas de la migración internacional en el Vale do Rio Doce por artículos domésticos}

Resumen: El artículo busca identificar y evidenciar marcas concretas y simbólicas de que la emigración en seis ciudades del Valle del Río Doce se inscribe en estos territorios por los sujetos y grupos que migran a los Estados Unidos. Para ello, activa las teorías de la migración internacional y las combina con estudios territoriales. También utiliza la fotografía con herramienta de investigación y lenguaje expositivo de los resultados anclados en Semiótica como metodología para analizar imágenes. En este artículo, se analiza la serie fotográfica de artículos para el hogar, revelando la existencia de aspectos sorprendentes que (re) configuran un territorio históricamente marcado por la experiencia de la migración.

Palabras clave: Emigración internacional. Territorio. Fotografía. Semiótica.

\section{Introdução}

O Vale do Rio Doce, no interior de Minas Gerais, é uma região reconhecida nacional e internacionalmente pela emigração de milhares de seus moradores, especialmente para os Estados Unidos. Esses fluxos, iniciados há mais de 50 anos, produzem efeitos consideráveis em todas as dimensões que estruturam a vida social dos moradores desses territórios, conforme demonstram estudos de Margolis (1994) e Siqueira (2009). As migrações continuadas originam práticas que se integram à cultura dessas populações e (re) configuram seus territórios. Essa dinâmica produz marcas indeléveis nos lugares onde ocorrem e nos sujeitos que ela envolve.

A cidade de Governador Valadares é a origem dos primeiros sujeitos a buscarem no emigração uma forma alternativa de trabalho e renda (MARGOLIS, 1994). Do final da década de 60 até os dias atuais, a constituição do fluxo emigratório a partir da cidade desencadeou processos que impactam o modo de vida dos habitantes dessa região, como relatam estudiosos do fenômeno migratório (MARGOLIS, 1994; ASSIS, 1995; SOARES, 1995; SIQUEIRA, 2009). Dos anos 1980 para cá, o Vale do Rio Doce tornou-se o principal ponto de partida de brasileiros para o exterior (SIQUEIRA, 2018). 
Nesse período, diversos efeitos foram verificados nas várias cidades de onde se originam os fluxos. Entre eles, alterações no cenário urbano e mercado imobiliário de Governador Valadares (MARTES; SOARES, 2006), e o surgimento de negócios empreendidos por emigrantes no município e cidades vizinhas (SIQUEIRA, 2009). A prática também fez surgir uma indústria da emigração (FAZITO, 2010), cujo braço ilegal gerou até uma Comissão Parlamentar Mista de Inquérito sobre o tráfico de pessoas, a CPI da Emigração Ilegal (BRASIL, 2006).

Todavia, efeitos menos ruidosos também são gerados pela migração continuada e impactam as vivências em toda uma região, cuja população é de mais de 1,5 milhão de pessoas (IBGE, 2010). A consolidação da migração como símbolo de sucesso é uma das consequências, bem como a valorização de tudo que vem dos EUA, seja material ou simbólico (SIQUEIRA, 2009). Os rearranjos familiares em função da ausência do emigrante e as rupturas sócioafetivas geradas em quem não migra (ASSIS, 1999) são também rastros deixados pela migração continuada nesse território.

O presente artigo tem por objetivo identificar e evidenciar as marcas materiais e imateriais que essa prática migratória para os EUA inscreve nos territórios de seis cidades do Vale do Rio Doce e nas territorialidades de seus habitantes. São elas: Sobrália, Fernandes Tourinho, Engenheiro Caldas, Conselheiro Pena, Governador Valadares e Ipatinga. Mais especificamente, buscouse salientar que elementos advindos da emigração informam o surgimento de novas territorialidades na vida dos sujeitos engendrados por essa diáspora em seus territórios locais.

Aqui se esclarece que o conceito de marca vem de uma das definições oferecidas pelo dicionário Houaiss (2017): "traço distintivo por que se reconhece alguém ou algo". Nesse mesmo sentido, de distinguir e reconhecer, o termo "marca" éutilizado pelo Dicionário de Semiótica (GREIMAS; COURTÉS, 2008, p. 272) para se referir aos "traços distintivos" ou "signos de reconhecimento" que se obtém a partir da presença de um elemento heterogêneo em um conjunto. 
Seja no ordenamento político e econômico ou na conformação cultural e social, a emigração continuada traz mudanças às dinâmicas sociais de sujeitos e territórios. Sua efetivação ao longo do tempo produz traços de comportamento distintos do padrão daquelas comunidades, atribuindo significados particulares ao processo, com amplos reflexos no território. Sondar alguns desses significados foi objeto de um estudo mais amplo, contudo, neste artigo, será tratado especificamente dos utensílios domésticos.

\section{As teorias das migrações e do território}

No percurso que levou à realização desta tarefa, os aportes teóricos sobre a migração internacional foram um alicerce imprescindível no cumprimento da proposta. Tais estudos dão conta da complexidade dos processos migratórios e tratam ainda de muitas das afetações que produzem nas sociedades em níveis macro e micro. Em especial nos Estados Unidos, de onde partem muitas das teorias aqui acionadas. Uma dessas ricas contribuições é o alerta feito por Massey et al (1993) de que a migração internacional, como objeto de estudo multidimensional e multifacetado, requer abordagens sensíveis que perpassem várias áreas do conhecimento. E análises que contemplem os vários níveis de amplitude e profundidade nos quais a migração se efetiva na prática.

Os padrões e tendências atuais da imigração, no entanto, sugerem que uma compreensão plena dos processos migratórios contemporâneos não será percebida, contando apenas com as ferramentas de uma disciplina, ou concentrando em um único nível de análise. Antes, sua natureza complexa e multifacetada requer uma teoria sofisticada que incorpore uma variedade de perspectivas, níveis e premissas. (MASSEY et al., 1993, p. 432) ${ }^{3}$.

${ }^{3}$ Tradução livre 
Tal assertiva é adotada como proposta heurística, pois ilumina duas questões caras a este estudo: a primeira é a defesa da interdisciplinaridade como única forma de enxergar com clareza o fenômeno da migração internacional e, por conseguinte, os efeitos que possa causar sua perpetuação a partir de um mesmo território de origem; a segunda questão é que se aplica aos estudos territoriais a mesma postura epistemológica integradora, que incorpora vários níveis de análises bem como perspectivas sugeridas em pressupostos de várias disciplinas.

Nesse sentido, os estudos territoriais apresentam-se como ferramenta teórica profícua para o entendimento das causas e afetações dos fluxos migratórios nos espaços onde ocorrem. Ao olhar para o território a partir das dimensões econômicas, jurídicopolíticas e simbólico-culturais, como postula Haesbaert (2004), os estudos territoriais permitem enxergar por partes as afetações espaciais dos fenômenos migratórios.

O acionamento dessas teorias - das migrações e do território - é feito ainda em consonância com pesquisas desenvolvidas sobre o tema em Governador Valadares e cidades vizinhas. Esses estudos apontam afetações econômicas, políticas e sociais em sujeitos e grupos nos territórios locais causadas pela migração continuada de alguns de seus moradores. E apontam como a migração internacional já se constitui prática normalizada, característica territorial desses municípios. Alguns desses estudos locais serão detalhados adiante e acionados nas análises das fotografias como forma de validação de hipóteses aventadas a partir das imagens.

\section{Metodologia: o caminho para as marcas}

Como postura, a pesquisa interdisciplinar sugere que o objeto seja o ponto de partida das abordagens teóricas e metodológicas (JAPIASSU, 1976). Nessa esteira, parte-se da busca pelas marcas da migração internacional para se pavimentar um caminho que seja possível identificá-las e evidenciá-las, bem ao estilo proposto por Becker (1999) como modelo artesanal de ciência. Na prática, busca-se ferramentas adequadas para atender ao propósito de se cumprir o objetivo do estudo. 
$|6|$

As marcas da migração internacional...

Sob essa ótica, a fotografia foi utilizada aqui como instrumento que permitiu evidenciar os elementos inseridos nos territórios dos emigrantes a partir do êxodo para os Estados Unidos de alguns dos seus habitantes. Não apenas como ferramenta prática, mas também como campo do conhecimento, a fotografia é acionada ainda enquanto linguagem para compor o discurso que expõe as marcas materiais da migração.

A utilização da fotografia em pesquisa se ampara nos postulados de Becker (1974; 1999), que a considera rico instrumento para investigação social. Para o autor, as experimentações do campo das artes é que devem ser incorporadas pelo contexto científico como complementaridade para que a ciência possa enxergar melhor o social como um todo. Becker (1974; 1999) propõe que haja um equilíbrio entre o rigor acadêmico que caminha para o hermetismo e o risco de um estatuto perigosamente científico para fotografias documentais em contexto de pesquisa social.

A riqueza de informações e a polissemia da imagem fotográfica são atributos ressaltados também por Martins (2008) e Schwarcz (2014), que defendem uma maior valorização do discurso fotográfico como gerador de conhecimento científico. Eles partilham com Samain (2000) e Achutti (2003), a ideia de que as imagens possam ser aplicadas na apresentação de resultados em pesquisas sociais. Caminho esse que o presente artigo buscou seguir.

Não menos conceitual e processual, a Semiótica de Peirce foi a metodologia de análise da narrativa fotográfica produzida por um dos pesquisadores durante a investigação. Sua condição de fenômeno (PEIRCE, 2005) viabilizou a proposição de inferências de significados em vários níveis, tanto dos signos visuais que constituem as imagens fotográficas, quanto dos objetos representados por esses signos.

Pelo seu caráter eminentemente teórico e filosófico (SANTAELLA, 2016), a Semiótica permitiu a articulação de seus pressupostos em compasso com os conhecimentos sobre o território abordado, com os estudos sobre a emigração nos territórios locais e com os potenciais expressivos da linguagem fotográfica. 


\section{Reflexos locais da migração}

Essa perspectiva teórica possibilitou explorar com significativo retorno o campo de pesquisa delimitado pelos municípios de Sobrália, Fernandes Tourinho, Engenheiro Caldas e Conselheiro Pena, além de Governador Valadares e Ipatinga. Os três primeiros municípios citados são contíguos e possuem as mais altas taxas de migração internacional do país, segundo o Censo demográfico do Instituto Brasileiro de Geografia e Estatítitica IBGE (2012). Os municípios de Ipatinga e Governador Valadares foram incluídos por serem de porte médio e servirem de referência regional para as dezenas de pequenos municípios de seus entornos (IBGE 2007). Também pesou o fato de Governador Valadares ser a principal cidade do Vale do Rio Doce e epicentro do fenômeno migratório e (SIQUEIRA, 2018).

Entre as cidades, o maior destaque é Sobrália, que possui 88,8 habitantes no exterior para cada 1.000 habitantes vivendo no município. Ou um número de emigrantes correspondente a $8,88 \%$ da população de 5.830 pessoas que vive no município (IBGE, 2012). Esses números fazem de Sobrália a campeã nacional de exportação de pessoas para o exterior ${ }^{4}$ e motivou sua adoção como território alvo desta pesquisa.

Com 3.030 habitantes, Fernandes Tourinho tem a menor população das cidades pesquisadas, mas é a terceira maior taxa de migração internacional, com 64,7 habitantes no exterior para cada 1.000 habitantes no município, segundo o IBGE (2012). O órgão apontou também 46,30 emigrantes de Engenheiro Caldas para cada 1.000 moradores do município, que tem 10.280 habitantes e ficou em décimo lugar no país no quesito emigração internacional. Além dos altos índices migratórios, esses três municípios são vizinhos separados por, no máximo, 13 quilômetros de estradas vicinais. Engenheiro Caldas é a referência entre eles, pois fica às margens da

\footnotetext{
${ }^{4}$ Todos os dados populacionais, bem como as taxas e os números absolutos referentes à emigração internacional dos municípios citados neste capítulo são do Censo Demográfico do IBGE (2010).
} 
$|8|$

As marcas da migração internacional...

BR-116 e cerca de 42 quilômetros de Governador Valadares - pela rodovia BR-116 sentido norte ${ }^{5}$.

O município de Conselheiro Pena não estava inicialmente entre os territórios selecionados, pois fica a $93 \mathrm{~km}$ de Governador Valadares pela rodovia MG 259, no sentido Colatina (ES). Porém, as investigações conduziram a pesquisa para a localidade de 22.242 habitantes, com taxa de migração internacional de 51,21 emigrantes para cada 1.000 moradores - a nona mais alta do país.

Os números proporcionais de Ipatinga e Governador Valadares não são significativos por terem populações de mais de 250 mil habitantes cada. No entanto, em termos absolutos, Governador Valadares tem números relevantes, com um total de 7.560 migrantes no exterior (IBGE, 2012), a sétima maior população brasileira fora do país, superando capitais como Brasília, Porto Alegre e Fortaleza.

Um survey realizado com imigrantes brasileiros no estado de Massachussets $^{6}$ (MARTES; SOARES, 2006) revelou que, do universo pesquisado, 78\% enviam remessas regulares ao Brasil. A pesquisa demonstra ainda que as remessas são destinadas prioritariamente para: ajuda familiar; compra de imóveis no Brasil, aplicação em investimentos financeiros e pagamentos de dívidas, além de doações a entidades.

Entre outros dados levantados pelo estudo, dois fatores se mostram significativos para este trabalho: i) os percentuais de $14 \%$ e $5 \%$ das remessas são destinados às cidades de Governador Valadares e Ipatinga, respectivamente; ii) o envio médio de recursos é da ordem de cerca de US\$ 6,5 mil anuais por migrante. Tais números foram obtidos em 2004 e, segundo o estudo, contribuíram para uma expansão imobiliária na cidade no período entre 1984

\footnotetext{
${ }^{5}$ Distâncias medidas pelo aplicativo de rotas através de georreferenciamento, oferecido pelo www.maps.google.com.

${ }^{6}$ A pesquisa de Martes e Soares, realizada em 2004 nos EUA, selecionou uma amostra de 235 brasileiros nas cidades de Cambridge e Sommerville, na região metropolitana da capital de Massachussets, além de 10 brasileiros donos de lojas de envios de remessas na própria cidade de Boston.
} 
e 1993, tendo nos emigrantes para os EUA os responsáveis por $35,9 \%$ das aquisições de imóveis nesse período.

Transportados para os dias atuais ${ }^{7}$, os valores de US\$ 6,5 mil apurados como valor médio enviado por emigrante a cada ano ainda são consideráveis. Representariam, atualmente, 0,87\% do PIB de Governador Valadares e 0,33\% do PIB de Ipatinga. Mais expressivos se tornam esses números quando aplicados às cidades de menor porte. Em Engenheiro Caldas, as remessas teriam participação de 2,85\% na riqueza produzida no município.

Em Fernandes Tourinho, elas representariam 3,86\% do PIB, enquanto em Sobrália, os valores chegariam a 6,80\% da riqueza anual local. Se a média apontada pelo estudo se mantiver, as remessas de dinheiro para Sobrália chegariam a mais de 50\% da atividade agropecuária do município. E somariam $148 \%$ de toda a atividade industrial registrada na cidade.

\section{Ao encontro das marcas}

A investigação exigiu a vivência dos territórios escolhidos e a convivência com os sujeitos marcados pela diáspora nessas localidades. Em um processo de busca ativa, a pesquisa acionou órgãos públicos, instituições religiosas, estabelecimentos comerciais e cidadãos comuns, em um diálogo que (re) configurou o território deste estudo.

Ao todo, foram 23 incursões pelo campo de pesquisa, com mais de 50 visitas a locais e pessoas que conduziram ao levantamento de informações e produção de fotos. A maior parte se concentrou em idas aos municípios de Sobrália, Fernandes Tourinho e Engenheiro Caldas pela relevância dos números apresentados acima e por serem localidades ainda pouco

\footnotetext{
${ }^{7} \mathrm{O}$ comparativo é feito com base no número de migrantes de cada município, apontado pelo IBGE (2012), e no PIB de 2016 de cada uma das cidades, divulgado pelo IBGE em sua página na internet (https://cidades.ibge.gov.br/), acessada em 9 de março de 2019. Esse índice, segundo o órgão, é apurado em parceria com órgãos estaduais e indicam o dinamismo econômico das cidades.
} 
visitadas por pesquisadores da migração, conforme os próprios colaboradores afirmaram.

A produção de todas as fotografias apresentadas ficou a cargo do pesquisador, todavia, com a participação dos colaboradores. $\mathrm{O}$ critério é que os participantes fossem transmigrantes ${ }^{8}$, emigrados retornados há menos de dois anos, e não-migrantes que tivessem algum parente de primeiro grau morando nos EUA. Aos que se dispuseram a colaborar, foi-lhes pedido que apresentassem algo que representasse para eles a migração internacional, dando aos sujeitos pesquisados a real condição de colaboradores da pesquisa. Ao todo, foram produzidas 64 fotos que foram divididas em oito séries fotográficas.

Em um recorte dos resultados dessa pesquisa, traz-se neste artigo as 13 fotos da série "Utensílios Domésticos". Tais fotografias são arranjadas em uma narrativa visual de forma a ressaltar e simbolizar marcas materiais e imateriais da emigração internacional nos municípios estudados. Como objetos enviados em remessas de emigrados, os utensílios são eles próprios indícios materiais da emigração internacional. Como relíquias ou troféus, eles simbolizam o sucesso do projeto migratório e a ausência do emigrante, marcas imateriais deixadas pela migração internacional nesses territórios.

As análises das fotos são feitas em pequenos conjuntos em conformidade com a forma de apresentação, em trípticos e polípticos, sendo que cada imagem é citada e analisada individualmente e no conjunto. $\mathrm{O}$ método de análise segue os pressupostos da lógica crítica da semiótica peirceana (SANTAELLA, 2016), que fornece modelos para a inferência e verificação de resultados.

São eles três tipos de raciocínio: i) o pensamento abdutivo, que permite conjecturas, sugestões, e formulação de verdades possíveis - hipóteses - sobre os significados das imagens

\footnotetext{
${ }^{8}$ Tal figura é caracterizada pelo sujeito que circula entre os diferentes territórios que a migração lhe permite articular, que se territorializa em movimento, sob uma perspectiva econômica transnacional (SCHILER, 1992) e ambiente transcultural (HALL, 2003).
} 
fotográficas; ii) o pensamento dedutivo, que permite apurar fatos, indícios, e formular verdades prováveis - assertivas - sobre o que diz as fotografias; iii) o pensamento indutivo, que permite verificar se as inferências abduzidas e deduzidas se confirmam em casos semelhantes e se podem ser aplicadas em outros casos parecidos, tornando-se a assertiva deduzida uma regra geral para os casos com as mesmas características determinadas pelo estudo.

Antes de se proceder à exposição das imagens, fazse necessário esclarecer que a análise da série fotográfica em questão não propõe um viés etnográfico para a abordagem dos utensílios como objetos resultantes de um processo migratório, o que, a propósito, se mostra bastante pertinente como proposta metodológica.

Contudo a presente série é um recorte de um ensaio fotográfico em que se aborda elementos de universos variados, tendo em comum o fato de constituírem parte do território e das territorialidades de sujeitos e grupos engendrados pelas dinâmicas da migração internacional no Vale do Rio Doce há mais de 50 anos.

Outra peculiaridade das fotos, consonante com o que postula Achutti (2003), é a estratégia discursiva de apresentar uma narração visual sem nenhum texto intercalado com as imagens para não desviar a atenção do espectador. Tal proposta se respalda ainda nas proposições de Scwarcz (2014) e Martins (2008) sobre a utilização de imagens para divulgação de resultados de pesquisas.

Os textos remissivos à série são apresentados após as fotos e trarão as respectivas análises. Antes de querer sobrepujar os textos às imagens ou vice-versa, tal formato pretende, antes, valorizar cada uma das linguagens - visual e escrita - ao permitir que haja uma fruição mais adequada dos códigos de informação que cada uma das linguagens carreia, como bem explica Samain (2000). 
As marcas da migração internacional...
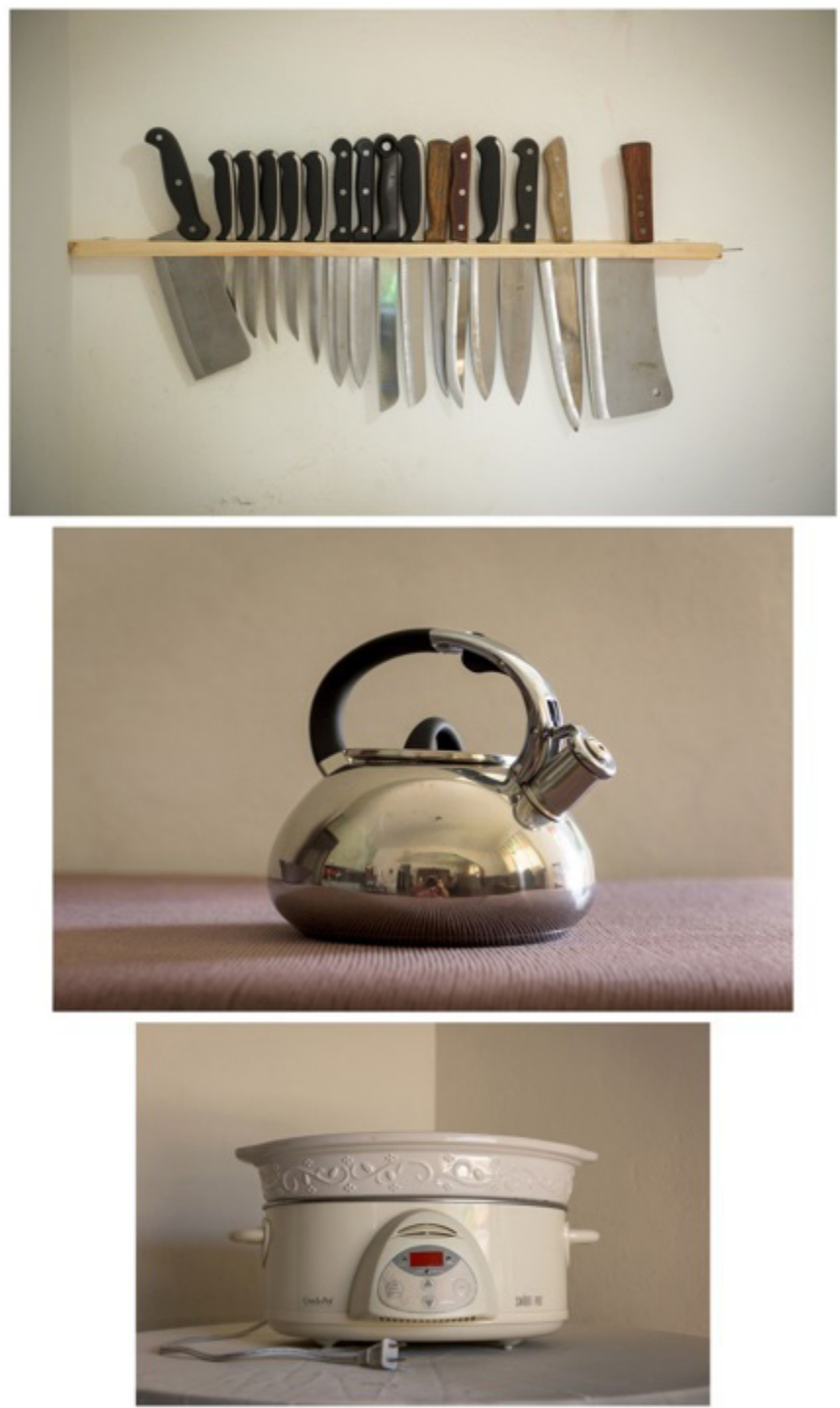

Figura 1: Tríptico Cozinha - Fotos Ricardo Alves, 2019. 
|13|

Ricardo Alves e Sueli Siqueira
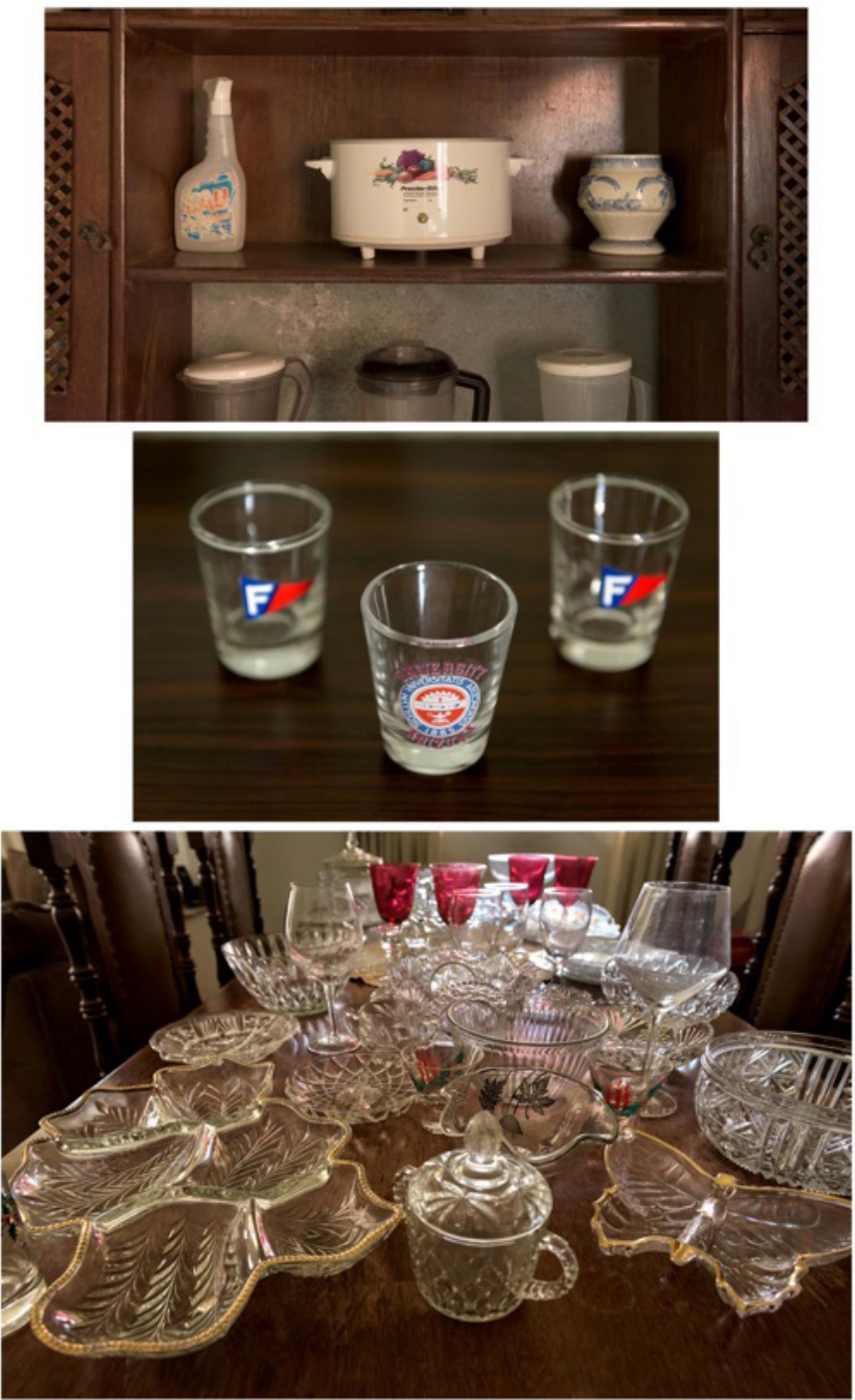

Figura 2: Tríptico Copa. Fotos Ricardo Alves, 2019. 
|14 |

As marcas da migração internacional...
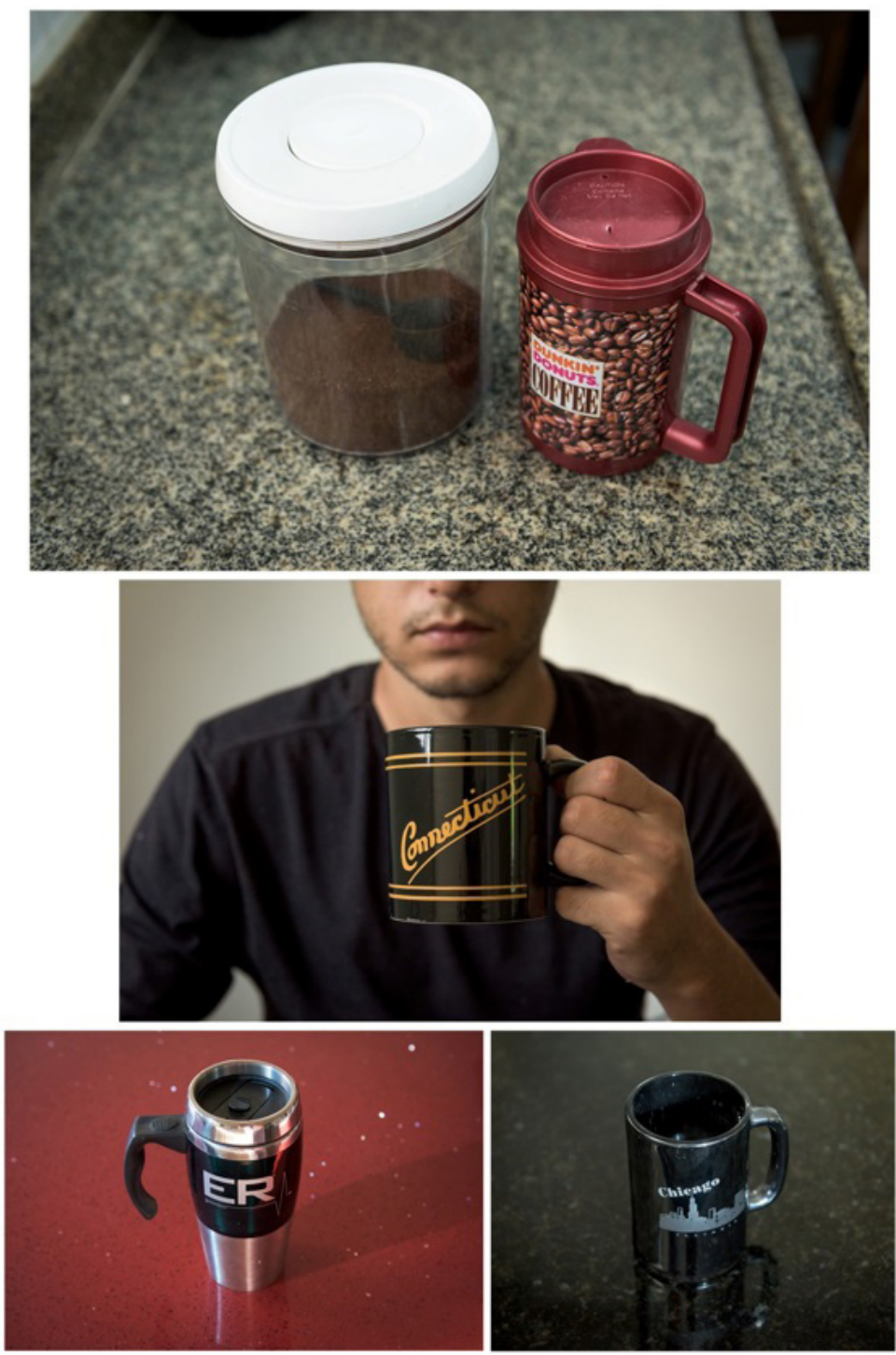

Figura 3: Políptico Café - Fotos: Ricardo Alves, 2019. 
$|15|$

Ricardo Alves e Sueli Siqueira

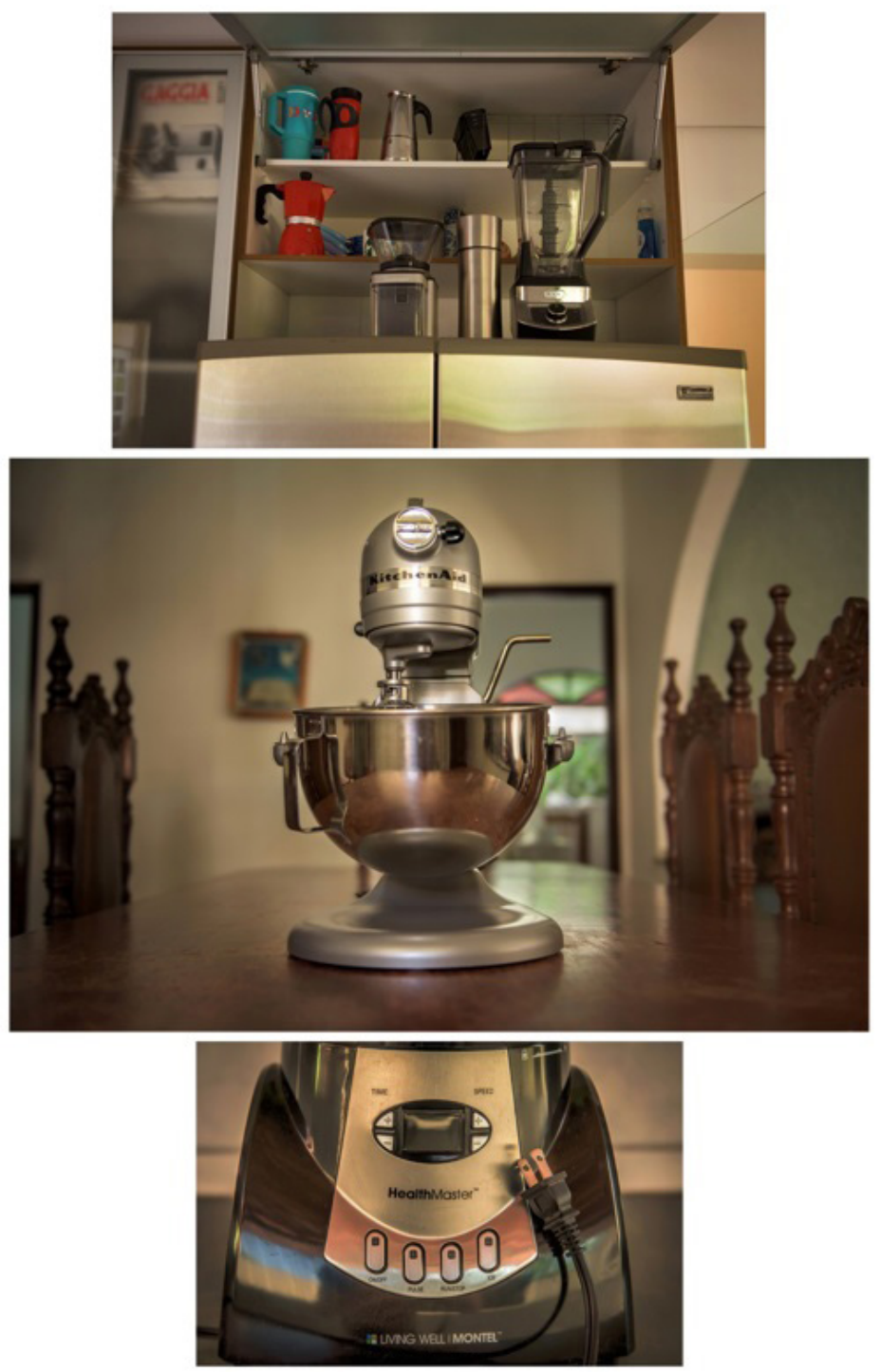

Figura 4: Tríptico Eletros. Fotos: Ricardo Alves, 2019 


\section{Resultados: análise da série fotográfica}

A série em análise trata de objetos trazidos dos Estados Unidos pelos migrantes em passeios, em seus retornos para a origem, ou mesmo enviados daquele país em remessas ou através de portadores. Esse objetos são chamados aqui de utensílios, pois são destinados ao uso doméstico e se referem, ao uso específico em atividades ligadas às refeições, que são uma forma de comunhão familiar.

A Figura 1 - Tríptico Cozinha - traz na foto superior um conjunto de 16 facas expostos em um suporte fixo na cozinha de uma casa. De variados tamanhos, tipos e finalidades, as facas não diferem muito dos mesmos utensílios brasileiros, exceto pela qualidade de uso alegada por seu dono. A foto do meio do tríptico exibe uma chaleira em aço inoxidável com alça superior fixa e um apito sonoro no bico, além de um botão de acionamento mecânico da tampa. Em raciocínio abdutivo, aventa-se que os dispositivos que sofisticam o uso de um utensílio de uso corriqueiro sugerem uma sofisticação de hábitos inserida no território local pelo artefato importado.

Na foto inferior, a imagem mostra uma panela elétrica, cujo funcionamento é operado por botões disposto em um painel frontal onde também tem um visor digital. O utensílio também traz a inscrição "Crock Pot" do lado esquerdo da foto, que se constatou ser a marca do produto. Do lado direito dessa foto, há a inscrição "Smart Pot" - "Panela Inteligente" em tradução livre - em referência à facilidade de uso. A tomada que pluga a panela na eletricidade também está à mostra e tem os pinos chatos, característica de produtos eletroeletrônicos importados dos EUA.

De modo discreto, essa primeira imagem da série alude a alguns hábitos cotidianos de emigrantes em diáspora, nos termos de Haesbaert (2012). E sugerem que esses hábitos contenham uma evolução intrínseca dos afazeres domésticos, uma sofisticação de métodos em comparação com os usos e vivências do território doméstico no Brasil. Em pensamento dedutivo, esta pode ser vista como uma das maneiras em que a migração carreia para os 
territórios locais os valores simbólicos de grandeza, de qualidade, de evolução, de superioridade e outros juízos sobre artefatos, hábitos e demais expressões da cultura dos Estados Unidos.

Tal pensamento se confirma, indutivamente, como regra quando se apura que a valorização do território estrangeiro e da sua territorialidade pelos emigrantes que cumpriram o objetivo de ascender economicamente se aplica também a casos semelhantes ainda não apurados (SIQUEIRA, 2009). Configura-se um típico caso de territorialidade simbólica do estrangeiro a definir parâmetros em territórios locais.

A segunda lâmina da série - Figura 2 - é um tríptico que chama a atenção pela quantidade de utensílios de vidro e cristal dispostos em uma mesa, exibidos pela foto inferior da imagem. São utensílios enviados dos EUA ano a ano por uma emigrante indocumentada naquele país e que vive há 15 anos sem vir ao Brasil. $\mathrm{O}$ acúmulo dos objetos sobre a mesa, mais que sugerir ou aludir (pensamento abdutivo), são um indício (pensamento dedutivo) do tempo acumulado na emigração e relatado por quem exibe os utensílios. Tempo de vida longe dos familiares e do território de origem, tempo esse contado pelas inúmeras remessas de encomendas e objetos que se acumulam.

A foto do meio da trinca exibe três pequenos copos, parte da coleção de utensílios da foto inferior. O copo do meio traz algumas inscrições referentes a uma universidade do estado do Arizona, nos Estados Unidos, indicando mais uma referência territorial estrangeira. Em diálogo com as duas citadas, a foto superior da imagem traz uma segunda panela elétrica, com a inscrição da marca e o desenho de alguns legumes. O modelo do utensílio exibe alguns desgastes pelo uso e tempo de fabricação, criando também um nexo temporal que evoca o período de tempo em que a migração (re) configura, continuamente, ambientes domésticos nos municípios pesquisados.

Sobre as temporalidades na migração, Georg Simmel (apud SIQUEIRA, 2009) postula a existência de um tempo suspenso, que não passa para os emigrantes, sujeitos mergulhados em uma circunstância de aventura. A esse respeito, Siqueira (2009) 
destaca que essa dinâmica se aplica aos migrantes dos territórios estudados, para os quais a vivência do tempo na migração parece não contar como tempo corrente de vida. Sayad (2000), por sua vez, fala do tempo que o migrante dedica ao lugar e ao tempo da sua partida, gerando um sentimento de nostalgia que o desloca do tempo diacrônico.

Essa ausência do emigrante em seu território de origem é a primeira e uma das mais profundas marcas geradas pela migração. Produz um estado paradoxal definido por Sayad (2000, p.20) como ausência-presença. Tal conceito explica uma condição em que o migrante "está nos fatos física, material e corporalmente ausente, mas está moral, mental, imaginária e espiritualmente presente". Essa ausência é sentida fortemente pelos "filhos da migração" (ALVES e DAIRREL, 2014), adolescentes da cidade de São Geraldo da Piedade que programam seus futuros nos Estados Unidos em função da emigração do pai ou da mãe.

A existência de casos semelhantes em se aplica a mesma condição (pensamento indutivo), é que dão à ausência um caráter geral de regra para casos semelhantes, como marca deixada pela emigração - e pelo migrante.

A Figura 3 faz menção a um hábito mundial, cultuado tanto no Brasil quanto nos Estados Unidos: o consumo de café. Com quatro fotos em um políptico, a imagem faz referência a diferentes espaços daquele pais - aqui em sentido amplo. A imagem dos utensílios de café mostra a presença de territorialidades múltiplas (HAESBAERT, 2004) que tocam a origem material e a dimensão cultural simbolizada pelos utensílios.

Na foto do meio, uma pessoa empunha uma caneca preta que tem escrito em cor de caramelo o nome do estado de Connecticut, nos EUA. Na foto inferior da direita, uma outra caneca preta está com o nome da cidade de Chicago impresso em cor prateada sobre a lateral do objeto. Dedutivamente, afirma-se que ambas expressam diferentes origens e territorialidades concretas em diferentes níveis geográficos.

A foto inferior esquerda exibe uma caneca prateada e preta sobre um fundo vermelho que salta aos olhos. O utensílio tem 
escrito "ER", iniciais de emergency room, ou sala de emergência em tradução livre, complementado pela presença de um gráfico de eletrocardiograma que acompanha as iniciais. As referências à prática da medicina nos Estados Unidos sugerem uma territorialidade simbólica estrangeira, deduzida também pela sigla em inglês.

A foto superior do conjunto traz uma caneca vermelha, oriunda da lanchonete Dunkin' Donuts, com o nome da loja e a inscrição Coffee dispostas sobre uma figura de grãos de café. Ao lado, uma vasilha transparente com pó de café oriundo de uma das lojas da rede de lanchonetes estadunidense, famosa por vender café e as rosquinhas típicas daquele país, os donuts.

O que se deduz a partir dessa foto é a assimilação, em territórios locais, de traços concretos da cultura de consumo dos Estados Unidos. E ainda uma alusão (abdução) ao consumo de donuts que passa pela valorização dos produtos oriundos da famosa rede de lojas de rosquinhas daquele país. Julga-se (dedução) que a transposição de territorialidades concretas e simbólicas dos EUA para o Brasil reflete a conquista de territórios estrangeiros. Atitudes semelhantes são descritas em Siqueira (2009) como uma espécie de selo que atesta o sucesso do projeto migratório, o que permite afirmar (indução) que tal valoração positiva do estrangeirismo tem caráter de regra entre os emigrantes pesquisados.

Fechando a série de utensílios, a quarta lâmina - Figura 4 - é composta por três fotos de eletrodomésticos estadunidenses. $\mathrm{Na}$ foto inferior, um liquidificador com o nome do fabricante e o modelo do produto escritos em inglês é exibido junto com o pino chato da tomada que o pluga na rede elétrica. Na foto superior, além de um liquidificador, há moedor de café, cafeteiras, canecas e garrafa de café, dispostos sobre um refrigerador prateado, todos produtos importados.

No centro da imagem, uma batedeira prateada cujo design arredondado alude aos típicos aparelhos eletrodomésticos dos anos 50 e 60 nos Estados Unidos, época de pujança econômica e social naquele país. O prateado dos utensílios é um elemento de unidade estética e sugere (abdução) avanço tecnológico. A exemplo 
da primeira lâmina da série, deduz-se a partir dessa imagem que a tecnologia importada confere um maior status à cozinha ou à casa de quem possui esses utensílios.

Novamente aqui se demonstra a valorização do que vem do estrangeiro, posturas de emigrantes confirmadas por Siqueira (2009) e Margolis (2004) em seus estudos realizados em Governador Valadares e região. Tal confirmação (indução) põe a exibição desses utensílios como uma marca material da migração e um símbolo do estrangeirismo, essa uma marca imaterial da emigração no Vale do Rio Doce.

Dessa forma, a série de imagens dedicada aos utensílios domésticos informa sobre a migração mais que a apreciação das imagens poderia sugerir. Por estarem ligados ao ambiente doméstico, esses objetos se conectam a profundas subjetividades - territorialidades - dos emigrantes e de seus grupos sociais. E tornam possíveis inferências lógicas sobre o significado da migração e a identificação das marcas que a diáspora inscreve nos territórios locais.

Nesse sentido, a simples presença desses utensílios e sua incorporação nas territorialidades domésticas locais, são marcas materiais. E são consideradas salientes por habitarem espaços tão íntimos na vida dos viventes desses territórios. Por outro lado, a ausência dos emigrantes e o estrangeirismo, significados abstratos acionados a partir da presente série fotográfica, são consideradas aqui como profundas marcas imateriais inscritas pela migração nos territórios investigados.

\section{Considerações finais}

Os mais de 50 anos de existência do fenômeno migratório nos territórios do Vale do Rio Doce tornam complexas as tentativas de mensurar as implicações das diásporas ocorridas a partir desses territórios. Mesmo em suas particularidades, a migração internacional, como prática social consolidada, engendra uma série de mecanismos que envolvem todas as dimensões sociais dos territórios onde ocorrem. Afetam, assim, a configuração desses 
territórios na dimensão da economia e do trabalho, na instituição ou no exercício de direitos e de seus poderes correlatos, e na expressão da cultura e circulação dos símbolos a ela correspondentes. Tudo ao mesmo tempo.

De tal forma que torna praticamente impossível obter a medida precisa da extensão que os efeitos da migração desencadeiam nesses espaços. Por esse motivo, a articulação dos estudos territoriais, a partir dos enquadramentos teóricos propostos principalmente por Haesbaert (2004; 2012), se mostrou profícua no sentido de permitir que o fenômeno migratório fosse analisado a partir das dimensões em que se manifesta, as mesmas que constituem os territórios nos quais ocorre.

O que a fotografia aqui torna visível são indícios de afetações territoriais provocadas pelos fluxos migratórios, que se nomeou como "marcas". Algumas dessas marcas são materiais e se oferecem à análise de forma mais direta. Pois aludem às dimensões econômica, política e cultural, que se articulam de forma integrada e contínua, no processo de configuração territorial no Vale do Rio Doce. Por outro lado, elas simbolizam territorialidades estrangeiras arraigadas em territórios locais a partir das relações que os emigrantes desenvolveram no contato com o território estrangeiro.

Nesse sentido, os utensílios representam o poder de consumo, o sucesso alcançado através da migração, mas simbolizam ainda o sonho de retorno dos migrantes em diáspora. Reificam a expressão de um território marcado pela ausência de alguns de seus habitantes. Ausência essa que provoca nos territórios locais a substituição desse emigrante por suas remessas de valores em dinheiro ou objetos enviados para os seus. Ausência essa que agencia ainda a reconfiguração do território familiar e afetivo de sujeitos que não migram.

Pode-se afirmar, pela continuidade do fenômeno, que um dos aspectos territoriais da migração internacional é a sua consolidação como territorialidade própria da população do Vale do Rio Doce. Por esses motivos, considera-se também que tal fenômeno, tanto no sentido estrito quanto no sentido amplo, é 
uma marca territorial dessa região. No sentido estrito, a prática migratória afeta estruturas econômicas, políticas e culturais e os mecanismos de poder que geram as configurações dos territórios aqui abordados. No sentido amplo, o fenômeno migratório se articula em simbiose com o território, passando a ser ele próprio o fenômeno migratório - uma articulação territorial desses espaços materiais e simbólicos.

\section{Referências}

ACHUTTI, L. E. R. Fotos e palavras, do campo aos livros. Studium, n. 12, p. 5-16, dez. 2019. Disponível em https://econtents.bc.unicamp.br/inpec/index.php/studium/article/view/11743. Acesso em: 12 fev. 2020.

ALVES, M. Z.; DAIRELL, J. Os filhos da migração: condição juvenil em um contexto de transnacionalismo. Revista Ponto e Vírgula. São Paulo, n. 17, p. 175-195, 2015.

ASSIS, G. O. Estar aqui... Estar lá: uma cartografia da emigração valadarense para os Estados Unidos. In: REIS, R. R. e SALES, T. Cenas do Brasil Migrante. São Paulo: Boitempo, 1999. 311 p.

BECKER, H. S. Métodos de Pesquisa em Ciências Sociais. Tradução de Marco Estevão e Renato Aguiar. 4.ed. São Paulo: Hucitec. 1999. 178 p.

BECKER, H. S. Photography and sociology. Studies in Anthropology of Visual Comunication. Pennsylvania, USA, v. 1, n. 1, p. 3-26, out. 1974.

FAZITO, D. Análise de Redes Sociais e Migração. Dois aspectos fundamentais do "retorno". Revista Brasileira de Ciências Sociais. São Paulo, v. 25, n. 72, p. 89-100, fev. 2010.

GREIMAS, A. J. e COURTÉS, J. Dicionário de Semiótica. Tradução de Alceu Dias de Lima et al. São Paulo: Cultrix, 1979. 493 p. 
HAESBAERT, R. Hibridismo cultural, "antropofagia" identitária e transterritorialidade. In: BARTHE-DELOIZY, F.; SERPA, A., orgs. Visões do Brasil: estudos culturais em Geografia [online]. Salvador: EDUFBA; Edições L'Harmattan, 2012, p. 27-46.

HAESBAERT, R. O mito da Desterritorialização: do fim dos territórios à multiterritorialidade. Rio de Janeiro: Bertrand Brasil, 2004. 396 p.

HALL, S. Pensando a diáspora: reflexões sobre a terra no exterior. In: HALL, S. Da Diáspora - Identidades e Mediações Culturais. Liv Sovik (org). Tradução de Adelaine La Guardia Resende. Belo Horizonte: UFMG, 2003. cap.1, p. 25-50. 434 p.

IBGE - Instituto Brasileiro de Geografia e Estatística. Censo Demográfico Brasileiro 2010. Características da população e dos domicílios. Rio de Janeiro: IBGE, 2011. 270 p. Disponível em https://biblioteca.ibge.gov.br/visualizacao/periodicos/93/cd_2010_ caracteristicas_populacao_domicilios.pdf. Acesso em: 9 fev. 2019.

IBGE - Instituto Brasileiro de Geografia e Estatística. Regiões de Influência das Cidades: 2007. Rio de Janeiro: IBGE, 2008. 201 p. Disponível em https://biblioteca.ibge.gov.br/index.php/bibliotecacatalogo?view=detalhes\&id=240677. Acesso em: 5 mar. 2019.

JAPIASSU, H. Interdisciplinaridade e Patologia do Saber. Rio de Janeiro: Imago. 1976. 220 p.

BRASIL. Congresso Nacional. Comissão Parlamentar Mista de Inquèrito da Emigração. Relatório Final da Comissão Parlamentar Mista de Inquérito. Brasília: Congresso Nacional, 2006. 577 p. Disponível em https://www.senado.gov.br/comissoes/CPI/ Emigracao/RelFinalCPMIEmigracao.pdf. Acesso em: 3 fev. 2020.

MARGOLIS, M. L. Little Brazil: imigrantes brasileiros em Nova York. Tradução de Luiza A. Araújo e Talia Bugel. Campinas: Papirus, 1994. $452 \mathrm{p}$.

MARTES, A. C. B; SOARES, W. Remessas de recursos dos imigrantes. Estudos Avançados. São Paulo, v. 20, n. 57, p. 41-54, mai/ago. 2006. 
MARTINS, J. S. Sociologia da Fotografia e da Imagem. São Paulo: Contexto, 2008. 208 p.

MASSEY, D. S. et al. Theories of international migration: a review and appraisal. Population and Development Review. New York, v. 19, n. 3, p. 431-466, 1993.

PEIRCE, C. S. Semiótica. São Paulo: Perspectiva, 2005. 337 p.

SAMAIN, E. Questões heurísticas em torno do uso das imagens nas ciências sociais. In: FELDMAN-BIANCO, B.; LEITE, M. L. M. Desafios da imagem. Fotografia, iconografia e vídeo nas ciências sociais. Campinas: Papirus, 1998, p. 51-62.

SAMAIN, E. Os riscos do texto e da imagem - em torno de Balinese Character (1942), de Gregory Bateson e Margaret Mead. Significação: Revista de Cultura Audiovisual, n.14, nov. 2000, p. 63-88. Disponível em https://doi.org/10.11606/issn.23167114.sig.2000.90617. Acesso em: 18 mar. 2019.

SANTAELLA, L. Semiótica Aplicada. 8aㅡ reimpr. da $1^{\underline{a}}$ ed. 2002. São Paulo: Cengage Learning, 2016. 186 p.

SAYAD, A. A imigração. Ou os paradoxos da alteridade. Tradução de Cristina Murachco. São Paulo: Edusp, 1998.

SAYAD, A. O retorno segundo Abdelmalek Sayad. Revista Travessia. São Paulo, v. Especial, p. 3-33, jan. 2000.

SCHILLER, N. G.; BASCH, L.; BLANC-SZANTON, C. Transnationalism: a new analitic framework for understanding migration. In: Annals of New York Academy of Science. Nova York, EUA , v. 645, n. 1, jul. 1992. Disponível em https://doi. org/10.1111/j.1749-6632.1992.tb33484.x. Acesso em: 10 dez. 2019.

SCHWARCZ, L. M. Agenciando imagens: o rei, a natureza e seus belos naturais. Sociologia \& Antropologia. Rio de Janeiro; v.4, n. 2, p. 391-431, outubro, 2014. 
SIQUEIRA, S. Histórico das migrações de Governador Valadares para os Estados Unidos. In: BOGUS, L.; BAENINGER, R. (org). A nova face da emigração internacional no Brasil. São Paulo: EDUC, 2018. 504 p.

SIQUEIRA, S. Sonhos, sucesso e frustrações na emigração de retorno: Brasil/Estados Unidos. Belo Horizonte: Argumentum, 2009. 